\title{
Phylogenetic characterization and proposal of a new pigmented species to the genus Prevotella: Prevotella pallens sp. nov.
}

\author{
Eija Könönen,, ${ }^{1}$ Erkki Eerola, ${ }^{2}$ Ellen V. G. Frandsen, ${ }^{3}$ Jari Jalava, ${ }^{2}$ \\ Jaana Mättơ, ${ }^{1,4}$ Saara Salmenlinna' and Hannele Jousimies-Somer ${ }^{1}$
}

Author for correspondence: Eija Könönen. Tel: +358 94744 8248. Fax: +35894744 8238.

\footnotetext{
1 Department of Bacteriology, National Public Health Institute, Mannerheimintie 166, FIN-00300 Helsinki, Finland

2 Department of Medical Microbiology, University of Turku, Turku, Finland

${ }^{3}$ Department of Oral Biology, Royal Dental College, University of Aarhus, Aarhus, Denmark

4 Scientific Laboratory, Institute of Dentistry, University of Helsinki, Helsinki, Finland
}

\begin{abstract}
Complete 16S rRNA gene sequences of three representative strains of anaerobic, Gram-negative, pigmented, moderately saccharolytic, indolepositive bacteria isolated from the oral cavity of humans were determined. According to comparative analyses of the rRNA sequence data, this organism represents a previously unknown species within the genus Prevotella. In addition, 22 representative strains and 21 reference strains (including 11 Prevotella intermedia and 10 Prevotella nigrescens strains) were subjected to multilocus enzyme electrophoretic analysis. The strains were consistently separated into three clearly distinct groups, corresponding to their previous entities. On the basis of the present phylogenetic results that confirmed our biochemical and genetic data, we propose a new species, Prevotella pallens. The type strain is NCTC 13042 ( = AHN 10371).
\end{abstract}

Keywords: Prevotella pallens sp. nov., oral bacteria, multilocus enzyme electrophoresis, 16S rRNA gene sequencing

\section{INTRODUCTION}

In the accompanying paper (6), we described a Gramnegative, anaerobic, pigmented species phenotypically most closely related to Prevotella intermedia and Prevotella nigrescens (11) and therefore tentatively called it a $P$. intermedia/nigrescens-like organism (PINLO). A negative lipase reaction on egg yolk agar and weak pigmentation on rabbit laked blood agar consistently distinguished PINLO isolates from $P$. intermedia and $P$. nigrescens type strains. Furthermore, cellular fatty acid cluster analyses, determination of malate dehydrogenase and glutamate dehydrogenase electrophoretic mobilities, hybridization with $P$. intermedia and $P$. nigrescens species-specific DNA oligonucleotide probes, and arbitrarily primed PCR, clearly separated PINLO from both $P$. intermedia ATCC $25611^{\mathrm{T}}$ and $P$. nigrescens ATCC $33563^{\mathrm{T}}(6)$. In the present paper we report the polyphasic characterization of PINLO, including a more comprehensive

Abbreviations: ET, electrophoretic type; MLEE, multilocus enzyme electrophoresis; PINLO, Prevotella intermedia/nigrescens-like organism.

The EMBL accession numbers for the 16S rRNA sequences reported in this paper are Y13105, Y13106 and Y13107 for P. pallens AHN $10371^{\top}$, AHN 9423 and AHN 8792, respectively. enzyme mobility profiling and 16S rRNA gene sequencing, to assess the phylogenetic position and taxonomic status of this organism. On the basis of the biochemical and genetic characterization presented in the accompanying paper (6) as well as the parallel phylogenetic characterization, we propose a new pigmented, moderately saccharolytic, indole-positive Prevotella species, Prevotella pallens.

\section{METHODS}

Bacterial strains. Of the 33 clinical PINLO isolates examined (6), 22 isolates from one subject each were included in the multilocus enzyme electrophoresis (MLEE) analysis. In addition, $11 P$. intermedia reference strains (CCUG $24041=\mathrm{ATCC} 25611^{\mathrm{T}}, \mathrm{AB} 13 \mathrm{af}, \mathrm{BK} 20, \mathrm{BK} 28, \mathrm{BK} 33, \mathrm{BK}$ 36, MH 7, MH 16, MMJ 1-23, OMZ 248 and OMZ 326) and $10 P$. nigrescens reference strains (NCTC 9338, BEF $3=$ NCTC 9336 $^{\mathrm{T}}$, BK 29, HG 65, MH 3, MH 11, MHS 1-18, MHS 1-20, OMZ 256 and OMZ 328) recently examined by Frandsen et al. (2) were run for comparison in MLEE analysis. Three PINLO strains (AHN 8792, AHN 9423 and AHN 10371) were further selected for 16S rRNA sequencing analysis. AHN 8792 and AHN 10371 originated from gingival crevices and from saliva of two unrelated young children, respectively, and AHN 9423 from saliva of a periodontally healthy woman. The GenBank accession numbers for $16 \mathrm{~S}$ rRNA sequences of the reference strains 
used for comparison in constructing the phylogenetic tree are L16468 $\left(P\right.$. intermedia ATCC $\left.25611^{\mathrm{T}}\right)$, X73965 $(P$. intermedia B422), L16479 ( $P$. nigrescens ATCC 25261), L16471 ( $P$. nigrescens ATCC $\left.33563^{\mathrm{T}}\right)$ and X73963 $(P$. nigrescens NCTC 9336 ${ }^{\mathrm{T}}$ ) (13).

Multilocus enzyme electrophoretic analysis. The analysis was performed as previously described by Selander et al. (10). Preparation of bacterial extracts was done as described by Frandsen et al. (2) except that sonication was done intermittently for $5 \mathrm{~min}$. Electromorphs (mobility variants) were determined for the following 10 metabolic enzymes [the buffer systems according to Selander et al. (10) are indicated in parentheses]: adenylate kinase (A), glutamate dehydrogenase (A), malate dehydrogenase (A), nucleoside phosphorylase (A), glyceraldehyde-3-phosphate dehydrogenase (G), glycyl-phenylalanine peptidase $(\mathrm{H})$, leucyl-glycyl-glycyl peptidase $(\mathrm{H})$, phenylalanine-leucyl peptidase $(\mathrm{H})$, phosphoglucose isomerase (I), and phosphoglucomutase (I). All substrates were obtained from Sigma. Determination of genetic diversity (h) at an enzyme locus among strains, i.e. the probability that two randomly chosen strains have different alleles of the locus, genetic distance between electrophoretic types (ET) and construction of the dendrogram were performed as previously described by Selander $e t$ al. (10) using a matrix of pairwise genetic distances between ETs and the program ETCLUS (kindly provided by T.S. Whittam, Department of Biology, Institute of Molecular Evolutionary Genetics, Pennsylvania State University, University Park, PA, USA). Absence of enzyme activity was treated as missing data.

Determination of $16 \mathrm{~S}$ rRNA gene sequences. Bacterial DNA was isolated and the 16S rRNA gene was amplified by PCR as described in detail by Jalava et al. (4). The PCR product consisting of approximately 1450 bases was sequenced as nine partly overlapping segments. The PCR and the sequencing primers were described by Jalava et al. (4). The segments were assembled using the GCG program (version 8.1-UNIX, Genetics Computer Group, Madison, WI, USA). The full $16 \mathrm{~S}$ gene sequences obtained were further compared to known Prevotella sequences obtained from the Ribosomal Database Project (7) and GenBank (1). The compared sequences were aligned using the PILEUP program of the GCG package. The distance matrix was calculated by the DNADIST program of the PHYLIP package (J. Felsenstein). The alignment was resampled 1000 times using SEQBOOT. The phylogenetic tree was constructed from the distance matrix using the neighbour-joining method (9) with NEIGHBOR. The results of the distance matrix analysis were treated with CONSENSE to produce the consensus tree. Finally the consensus tree was drawn with DRAWGRAM. The SEQBOOT, NEIGHBOR, CONSENSE and DRAWGRAM programs belong to the PHYLIP package.

\section{RESULTS AND DISCUSSION}

Altogether, 22 PINLO strains and 21 reference strains of $P$. intermedia and $P$. nigrescens were characterized by the electrophoretic mobility of 10 intracellular metabolic enzymes (detailed data available upon request). In order not to induce a bias in the phylogenetic relations, each person was represented by one strain only. One mother-child pair shared an identical MLEE profile, so only one strain was analysed further. Thus, 21 PINLO strains were included in the calculations and the construction of the dendrogram.
Leucyl-glycyl-glycyl peptidase was monomorphic, while the remaining nine enzymes were polymorphic with 3-10 alleles per locus (Table 1). The mean number of alleles per locus was $5 \cdot 1$ and the mean genetic diversity per locus was 0.59 . A total of 35 ETs were identified, each characterized by a distinct combination of the electrophoretic mobilities of the 10 enzymes. Six ETs were represented by two strains, one ET by three strains, and the remaining 35 ETs by one strain (Fig. 1). The genetic distance between ETs, calculated as the proportion of the 10 enzyme loci at which dissimilar alleles were present, was used to construct the dendrogram shown in Fig. 1. The smallest genetic distance between ETs was 0.09 corresponding to a different mobility of a single enzyme. The dendrogram revealed three major lineages, termed divisions A, B and C, separating at genetic distances of 0.78 and 0.70 . Division A contained only reference strains of $P$. nigrescens and division B only reference strains of $P$. intermedia. All PINLO strains clustered in division $\mathrm{C}$. The significance of the two subdivisions in division $\mathrm{C}$ (segregating at a genetic distance of 0.51 ) is not known since the sub-grouping was not observed with other tests applied to all strains (6). According to the present results from MLEE based on 10 enzymes, PINLO constitutes a population distinct from those of $P$. intermedia and $P$. nigrescens.

Approximately all 1450 bases of the 16S rRNA sequence were determined for each of the three PINLO test strains. The sequences were compared with those of selected reference strains mostly belonging to the genus Prevotella available from local sequence database. On the basis of the branching position in the phylogenetic tree derived by the neighbour-joining method (9), PINLO belongs to the genus Prevotella. However, the present data also shows that PINLO differs from any of the previously described Prevotella species. PINLO test strains were most closely related to phenotypically similar $P$. intermedia and $P$. nigrescens reference strains in the phylogenetic dendrogram where the significance of the branching order was estimated by bootstrapping values (Fig. 2). In the present study, sequence similarities between the closest match, $P$. intermedia ATCC 25611 (GenBank accession no. L16468) and the PINLO test strains AHN 8792, AHN 9423 and AHN 10371, were 92.59, 93.48 and $92.94 \%$, respectively (detailed data available upon request). According to Stackebrandt \& Goebel (12), strains showing $16 \mathrm{~S}$ rRNA sequence similarity less than $97 \%$ will not show DNA-DNA reassociation more than $60 \%$ and will thus represent different species. In addition, as the sequence similarity of $94.7 \%$ between $P$. intermedia and $P$. nigrescens ( 8 ) is regarded as a distinct species criterion, it is obvious that the present $16 \mathrm{~S}$ rRNA sequence comparison clearly separated PINLO from these closely related Prevotella species.

The sequencing results substantiated by the MLEE analysis confirm that PINLO represents a population phylogenetically distinct from other related species. 
Table 1. Numbers of electrophoretic alleles and levels of genetic diversity per enzyme locus for 42 strains belonging to $P$. intermedia, P. nigrescens and the PINLO group

\begin{tabular}{|c|c|c|c|c|c|c|c|c|c|c|c|}
\hline \multirow{2}{*}{$\begin{array}{l}\text { Enzyme } \\
\text { locus* }\end{array}$} & \multicolumn{10}{|c|}{ Frequency of allele: } & \multirow{2}{*}{$\begin{array}{c}\text { Genetic } \\
\text { diversity } \dagger\end{array}$} \\
\hline & 1 & 2 & 3 & 4 & 5 & 6 & 7 & 8 & 9 & 10 & \\
\hline ADK & $0 \cdot 31$ & $0 \cdot 34$ & $0 \cdot 29$ & 0.06 & & & & & & & 0.69 \\
\hline $\mathrm{GDH}$ & 0.26 & $0 \cdot 17$ & 0.24 & 0.33 & & & & & & & 0.73 \\
\hline $\mathrm{MDH}$ & 0.49 & $0 \cdot 22$ & 0.05 & 0.24 & & & & & & & 0.64 \\
\hline NSP & $0 \cdot 24$ & $0 \cdot 38$ & 0.02 & 0.02 & $0 \cdot 17$ & $0 \cdot 14$ & 0.02 & & & & 0.74 \\
\hline GP1 & $0 \cdot 30$ & $0 \cdot 28$ & $0 \cdot 13$ & 0.03 & $0 \cdot 13$ & 0.03 & 0.08 & 0.05 & & & 0.79 \\
\hline GP2 & 0.71 & $0 \cdot 19$ & $0 \cdot 10$ & & & & & & & & 0.44 \\
\hline LGG & 1.00 & & & & & & & & & & $0 \cdot 00$ \\
\hline PLP & 0.69 & $0 \cdot 19$ & $0 \cdot 10$ & 0.02 & & & & & & & 0.47 \\
\hline PGI & $0 \cdot 12$ & $0 \cdot 12$ & $0 \cdot 50$ & $0 \cdot 17$ & 0.02 & 0.05 & 0.02 & & & & 0.69 \\
\hline PGM & $0 \cdot 15$ & 0.07 & 0.02 & 0.44 & 0.02 & 0.02 & 0.02 & $0 \cdot 20$ & 0.02 & 0.02 & 0.73 \\
\hline
\end{tabular}

* ADK, Adenylate kinase; GDH, glutamate dehydrogenase; MDH, malate dehydrogenase; NSP, nucleoside phosphorylase; GP1, glyceraldehyde-3-phosphate dehydrogenase; GP2, glycyl-phenylalanine peptidase; LGG, leucyl-glycyl-glycyl peptidase; PLP, phenylalanine-leucyl peptidase; PGI, phosphoglucose isomerase; PGM, phosphoglucomutase.

$\uparrow$ The mean genetic diversity for all enzyme loci was $0 \cdot 59$.

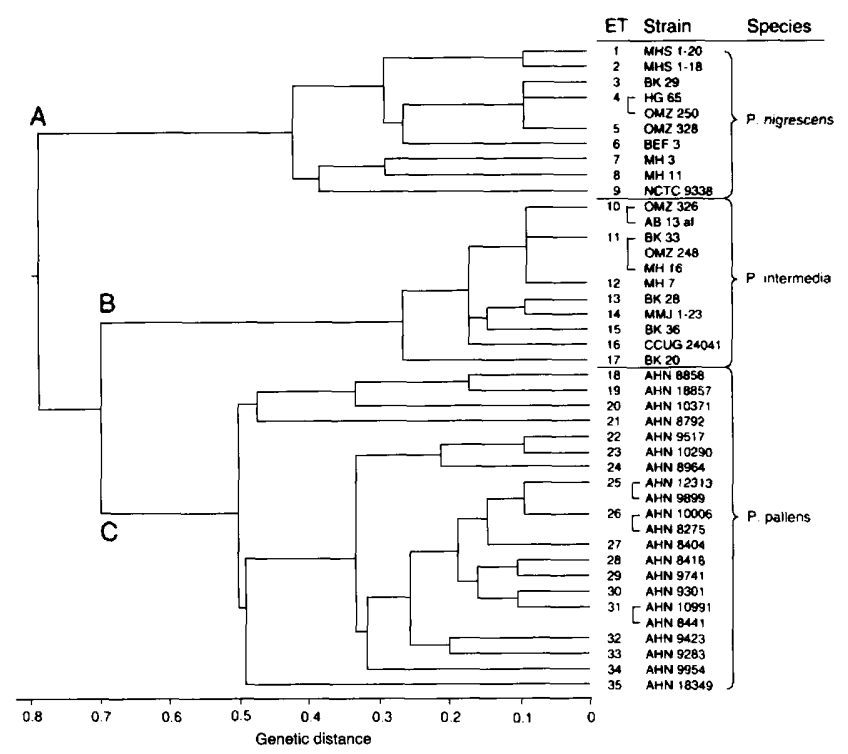

Fig. 1. Genetic relationships among 42 strains based on MLEE data. Three major divisions separating at genetic distances 0.78 and 0.70 are indicated at the left. The columns on the right show ETs, strain designation and affiliations.

On the basis of these results combined with biochemical and genetic characteristics of PINLO (6), we propose a new pigmented species, Prevotella pallens, to be included in the genus Prevotella.

\section{Description of Prevotella pallens sp. nov.}

Prevotella pallens (pal'lens. L. v. part. pallere to pale, referring to the weak pigmentation of colonies on blood agar plates).

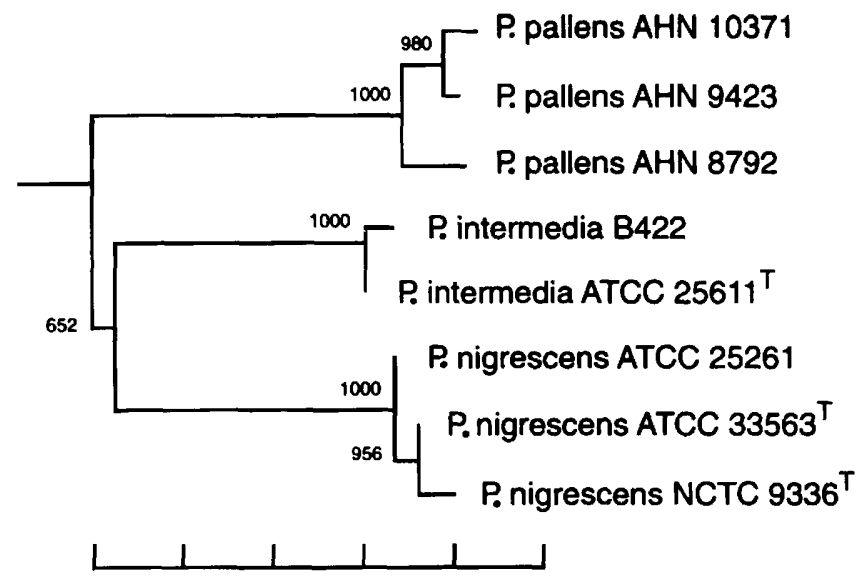

Fig. 2. Phylogenetic dendrogram produced using the neighbour-joining method showing the position of the proposed $P$. pallens strains (AHN 8792, AHN 9423, AHN 10371) in relation to $P$. intermedia and $P$. nigrescens strains. The scale bar represents a $5 \%$ difference in nucleotide sequence, determined by taking the sum of all the horizontal lines connecting two species.

The following description is based partly on the results presented in the accompanying paper (6). Cells are obligatory anaerobic, non-sporing, non-motile, Gramnegative rods or coccobacilli. Cells grown in broth cultures are $0.5-0.8 \times 1 \cdot 2-2 \mu \mathrm{m}$. Surface colonies on supplemented Brucella sheep blood agar plates after $3 \mathrm{~d}$ are $0.8-1.4 \mathrm{~mm}$ in diameter, circular, entire, raised convex, smooth and glistening. A distinct halo of metallic sheen is seen around the colonies. After 3-5 d incubation, colonies are weakly pigmented (cream); 
Table 2. Characteristics that differentiate $P$. pallens from phylogenetically closely related Prevotella species

Data from references $3,5,6,11$.

\begin{tabular}{|c|c|c|c|c|c|c|c|c|}
\hline \multirow[t]{2}{*}{ Prevotella spp. } & \multirow{2}{*}{$\begin{array}{c}\text { Pigment } \\
\text { production }\end{array}$} & \multirow{2}{*}{$\begin{array}{c}\text { Indole } \\
\text { production }\end{array}$} & \multirow{2}{*}{$\begin{array}{c}\text { Lipase } \\
\text { production }\end{array}$} & \multicolumn{3}{|c|}{ Acid produced from: } & \multirow[t]{2}{*}{$\alpha$-Fucosidase } & \multirow{2}{*}{$\begin{array}{c}N \text {-acetyl- } \beta \text { - } \\
\text { glucosaminidase }\end{array}$} \\
\hline & & & & Glucose & Lactose & Sucrose & & \\
\hline P. pallens & + & + & - & + & $-\dagger$ & + & $+\dot{t}$ & - \\
\hline P. nigrescens & $++^{*}$ & + & + & + & $-\dagger$ & + & $+\ddagger$ & - \\
\hline$P$. intermedia & $+t$ & + & + & + & $-\dagger$ & + & $+\ddagger$ & - \\
\hline P. disiens & - & - & - & + & - & - & - & - \\
\hline P. corporis & $+1++$ & - & - & + & - & - & - & - \\
\hline
\end{tabular}

$*++$, Black.

† Occasional lactose-fermenting strains may occur.

¥ Reaction always positive by Rosco Diagnostic Tablets; some strains negative by API ZYM.

on rabbit laked blood agar colonies are tan to light brown exhibiting red fluorescence under long-wave UV light (365 nm).

Acid is produced from glucose, maltose and sucrose in prereduced anaerobically sterilized peptone-yeast extract broth (PYG). Carbohydrate fermentation is not demonstrated from arabinose, cellobiose, aesculin, lactose (except one strain) and xylose. Gelatin is liquefied. Strains are indole-positive but lipase-negative. The major end-products of glucose fermentation are acetic and succinic acids; isovaleric acid is also frequently produced. Alkaline and acid phosphatases, phosphohydrolase, $\alpha$-glucosidase, and $\alpha$-fucosidase are positive, whereas $\alpha$-galactosidase, $\beta$-galactosidase (except for one strain), $\beta$-glucuronidase, $\beta$-glucosidase, $N$-acetyl- $\beta$-glucosaminidase and $\alpha$-mannosidase are negative. Table 2 summarizes distinctive biochemical and enzymic key reactions of $P$. pallens and biochemically and phylogenetically closely related Prevotella species. The major cellular fatty acids are anteiso$\mathrm{C}_{15: 0}$, iso- $\mathrm{C}_{15: 0}$, iso-3-OH $\mathrm{C}_{17: 0}$, and an unknown cellular fatty acid with equivalent chain-length at 13.570 , presented in descending quantitative order.

The strains are resistant to vancomycin but susceptible to colistin as determined by the special-potency antimicrobial disk profiles. Susceptibility to kanamycin, sodium polyanethol sulfonate and penicillin varies. Strains with decreased susceptibility to penicillin ( $>40 \%$ of strains, including the type strain) produced $\beta$-lactamase. The type strain of $P$. pallens is NCTC 13042 (= AHN 10371).

\section{ACKNOWLEDGEMENTS}

The authors are grateful to Drs Reijo Pitkäranta and Antti Arjava, Institute of Classical Philology, University of Helsinki, Finland, for helping to name P. pallens. We also thank Anne Peippo and Kirsti Tuomela for their technical assistance. The financial support from the Academy of Finland, the Finnish Dental Society, the Finnish Cultural Foundation and the Novo Nordisk Foundation are highly appreciated.

\section{REFERENCES}

1. Benson, D., Lipman, D. J. \& Ostell, J. (1993). GenBank. Nucleic Acids Res 21, 2963-2965.

2. Frandsen, E. V. G., Poulsen, K. \& Kilian, M. (1995). Confirmation of the species Prevotella intermedia and Prevotella nigrescens. Int $J$ Syst Bacteriol 45, 429-435.

3. Fukushima, H., Moroi, H., Inoue, J., Onoe, T., Ezaki, T., Yabuuchi, E., Leung, K.-L., Walker, C. B., Clark, W. B. \& Sagawa, H. (1992). Phenotypic characteristics and DNA relatedness in Prevotella intermedia and similar organisms. Oral Microbiol Immunol 7, 60-64.

4. Jalava, J., Kotilainen, P., Nikkari, S., Skurnik, M., Vanttinen, E., Lehtonen, O.-P., Eerola, E. \& Toivanen, P. (1995). Use of the polymerase chain reaction and DNA sequencing for detection of Bartonella quintana in the aortic valve of a patient with culture-negative infective endocarditis. Clin Infect Dis 21, 891-896.

5. Jousimies-Somer, H. R., Summanen, P. H. \& Finegold, S. M. (1995). Bacteroides, Porphyromonas, Prevotella, Fusobacterium, and other anaerobic gram-negative bacteria. In Manual of Clinical Microbiology, 6th edn, pp. 603-620. Edited by P. R. Murray. Washington, DC: American Society for Microbiology.

6. Könönen, E., Mättö, J., Văisănen-Tunkelrott, M.-L., Frandsen, E. V. G., Helander, I., Asikainen, S., Finegold, S. M. \& Jousimies-Somer, H. (1998). Biochemical and genetic characterization of a Prevotella intermedia/nigrescens-like organism. Int $J$ Syst Bacteriol 48, 39-46.

7. Maidak, B. L., Olsen, G. J., Larsen, N., Overbeek, R., McCaughey, M. J. \& Woese, C. R. (1996). The Ribosomal Database Project (RDP). Nucleic Acids Res 24, 82-85.

8. Paster, B. J., Dewhirst, F. E., Olsen, I. \& Fraser, G. J. (1994). Phylogeny of Bacteroides, Prevotella, and Porphyromonas spp. and related bacteria. J Bacteriol 176, 725-732.

9. Saitou, N. \& Nei, M. (1987). The neighbor-joining method: a new method for reconstructing phylogenetic trees. Mol Biol Evol 4, 406-425.

10. Selander, R. K., Caugant, D. A., Ochman, H., Musser, J. M., Gilmour, M. N. \& Whittam, T. S. (1968). Methods of multilocus enzyme electrophoresis for bacterial population genetics and systematics. Appl Environ Microbiol 51, 873-884.

11. Shah, H. N. \& Gharbia, S. E. (1992). Biochemical and chemical 
studies on strains designated Prevotella intermedia and proposal of a new pigmented species, Prevotella nigrescens sp. nov. Int $J$ Syst Bacteriol 42, 542-546.

12. Stackebrandt, E. \& Goebel, B. M. (1994). Taxonomic note: a place for DNA-DNA reassociation and $16 \mathrm{~S}$ rRNA sequence analysis in the present species definition in bacteriology. Int J Syst Bacteriol 44, 846-849.

13. Stoesser, G., Sterk, P., Tuli, M. A., Stoehr, P. J. \& Cameron, G. N. (1997). The EMBL nucleotide sequence database. Nucleic Acids Res 25, 7-13. 